\title{
Boosting photovoltaic properties and intrinsic stability for MA-based perovskite solar cells by incorporating 1,1,1-trimethylhydrazinium cation
}

Guozhen Liu, ${ }^{\text {ab }}$ Shendong $\mathrm{Xu},{ }^{\text {ab }}$ Haiying Zheng, ${ }^{\text {ab }}$ Xiaoxiao $\mathrm{Xu},{ }^{\text {ab }}$ Huifen $\mathrm{Xu},{ }^{\text {a }}$ Liying Zhang, ${ }^{\text {ab }}$ Xianxi Zhang, ${ }^{\mathrm{c}}$ Fantai Kong, ${ }^{\mathrm{a}} \mathrm{Xu}$ Pan*a

${ }^{a}$ Key Laboratory of Photovoltaic and Energy Conservation Materials, Institute of Applied Technology, Hefei Institutes of Physical Science, Chinese Academy of Sciences, Hefei 230031, China.

${ }^{b}$ University of Science and Technology of China, Hefei 230026, China.

${ }^{c}$ Shandong Provincial Key Laboratory/Collaborative Innovation Center of Chemical Energy Storage \& Novel Cell Technology, School of Chemistry and Chemical Engineering, Liaocheng University, Liaocheng 252000, China.

\section{Corresponding Authors}

*E-mail: xpan@rntek.cas.cn 


\section{Experimental Section}

\section{Materials and preparation}

Methylazanium iodide (MAI) were synthesized via the reaction of hydroiodic acid with methylamine ethanol solution. The detailed preparation process can be found in the ESI of ref. 29. The spiro-MeOTAD purchased from Xi'an Polymer Light Technology Corp. The solvents such as N,N-dimethylformamide (DMF), dimethylsulfoxide (DMSO), isopropanol and chlorobenzene acquired from Sinopharm. The lead(II) iodide $\left(\mathrm{PbI}_{2}\right)$ acquired from TCI. The lithium bis (trifluoromethylsulphonyl) imide (Li-TFSI), titanium isopropoxide, bis(acetylacetonate), hydroiodic acid and 4-tert-butylpyridine (tBP) purchased from Aldrich. Other materials have been acquired from Sinopharm or Alfa and these materials were used as received without additional treatment.

\section{Perovskite Solar Cells Fabrication}

FTO was respectively sonicated in cleaning agent and ultrapure water, and then respectively rinsed by ultrapure water and ethanol several times. The compact $\mathrm{TiO}_{2}$ was fabricated via spray pyrolysis solution at $460{ }^{\circ} \mathrm{C}$. The precursor consists of titanium diisopropoxide $(0.6 \mathrm{~mL})$, bis(acetylacetonate) $(0.4 \mathrm{~mL})$ and isopropanol $(7 \mathrm{~mL})$. The mesoporous $\mathrm{TiO}_{2}$ layer was spin-coated on the surface of compact layer at 4000 r.p.m. for $20 \mathrm{~s}$. The $\mathrm{TiO}_{2}$ paste of $30 \mathrm{~nm}$ was dispersed by adding 5.5 times ethanol. Then, mesoporous $\mathrm{TiO}_{2}$ layer was annealed at $510{ }^{\circ} \mathrm{C}$ for about $0.5 \mathrm{~h}$. The perovskite precursor solutions $\left(1.3 \mathrm{M} \mathrm{Pb}^{2+}\right)$ of $\mathrm{MAPbI}_{3}$ and $(\mathrm{TMH})_{\mathrm{x}} \mathrm{MA}_{1-\mathrm{x}} \mathrm{PbI}_{3}(\mathrm{x}=2.5 \%, 5 \%, 7.5 \%, 10 \%, 20 \%$ and $50 \%)$ were acquired via the dissolving of the corresponding components in mixed solvent of DMF and DMSO (a volume ratio of 4:1) and then stirred at $60^{\circ} \mathrm{C}$ for $40 \mathrm{~min}$. In glovebox with controlled-humidity air, the perovskite layers were spin-coated on the $\mathrm{TiO}_{2}$ layer by two processes (1100 r.p.m. for $13 \mathrm{~s}$ and 4600 r.p.m. for $35 \mathrm{~s}$ ). In the final $15 \mathrm{~s}$, chlorobenzene of about $100 \mu \mathrm{L}$ was quickly dripped on the perovskite layer. Next, the films were annealed 
at $100{ }^{\circ} \mathrm{C}$ for about $60 \mathrm{~min}$. The hole transport layer solution of spiro-OMeTAD $(73.5 \mathrm{mg})$, chlorobenzene $(1 \mathrm{~mL})$ and 4-tert-butylpyridine $(29 \mu \mathrm{L}), \mathrm{Li}^{+}$salt $(17 \mu \mathrm{L})$ and cobalt (III) salt $(8 \mu \mathrm{L})$ was coated on the perovskite layer at 3000 r.p.m. for 20 s. Finally, $60 \mathrm{~nm}$ of gold electrode was thermally evaporated on the HTM layer.

\section{Characterizations}

XRD patterns were carried out on a Smartlab 9KW. XPS data was measured on a Thermo ESCALAB 250Xi system. The UV-vis absorption spectra were measured on an ultraviolet-vis (UV-vis) spectrophotometer (U-3900H, HITACHI, Japan). PL spectra were measured with a standard 450 W Xenon CW lamp. The data was recorded on a Spectro fluorometer (photon technology international) and analyzed by the software Fluorescence. An LKS (Applied photophysics) with laser device energy of $150 \mu \mathrm{J} / \mathrm{cm}^{2}$ and repetition rate of $5 \mathrm{~Hz}$ was used to record the TA spectra with a probe light of $760 \mathrm{~nm}$ and a laser light of $500 \mathrm{~nm}$. EIS at $-0.8 \mathrm{~V}$ was tested on an Autolab analyzer (Metrohm, PGSTAT 302N, Switzerland) in the dark with a frequency range from $10 \mathrm{~Hz}$ to $1 \mathrm{MHz}$. SEM images were performed on a field-emission scanning electron microscope (FE-SEM, sirion200, FEI Corp., Holland) with high-resolution. $J-V$ curves and PCEs were obtained via using a solar simulator (Newport, Oriel Class A, 91195A) and a source meter (Keithley 2420). The solar simulator with $100 \mathrm{~mW} / \mathrm{cm}^{2}$ illumination AM 1.5G was calibrated via a Sireference cell which was certified by NREL. The devices retained an active area of $0.09 \mathrm{~cm}^{2}$. IPCE were performed on dual Xenon/quartz halogen light source (PV Measurements, Inc.) with a wavelength range from 300 to $850 \mathrm{~nm}$, and measured in DC mode with no bias light used. The water contact angles were gained using the contact angle measuring instrument (OCA15EC, Dataphysics, Germany).

\section{Aging measurements}

The humidity aging tests were measured in three containers which retained the humidity of about $45 \pm 5 \% \%$ 
in the dark and at room temperature. Heat aging test was performed at $85^{\circ} \mathrm{C}$ in a container. The container with about $10 \%$ RH was placed in the dark. UV light aging measurement was also carried out in a container with continuous UV irradiation. The UV light source (UV-Hg-2000, Beijing Lighting Research Institute) has a wavelength of about $360 \mathrm{~nm}$ and generated around 3-4 times the amount of UV light in AM1.5G spectrum.

Sisler et al. ${ }^{1}$ proved that average C-N distances and N-N distance in $\mathrm{TMH}^{+},\left[\left(\mathrm{CH}_{3}\right)_{3} \mathrm{NNH}_{3}\right]^{+}$, are 149 pm and $146 \mathrm{pm}$, respectively. It declares that $\mathrm{TMH}^{+}$and tetramethylammonium, $\left[\left(\mathrm{CH}_{3}\right)_{4} \mathrm{~N}\right]^{+}$, are very similar in radius. Furthermore, Mitzi et al. ${ }^{2}$ reported tetramethylammonium owns an effective radius of 292 pm. Finally, based on the Goldschmidt's tolerance factor rule, $\mathrm{TMHPbI}_{3}$ gives a tolerance of about "1.07", which will be complementary to the low tolerance factor of $\mathrm{MAPbI}_{3}$ (" 0.91 ") and then enhance the structure stability.

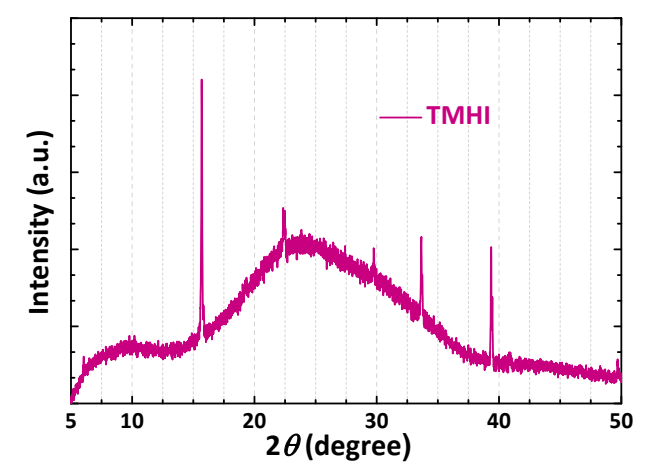

Figure S1. XRD patterns of 1,1,1-Trimethylhydrazinium (TMHI) films. 
(a)

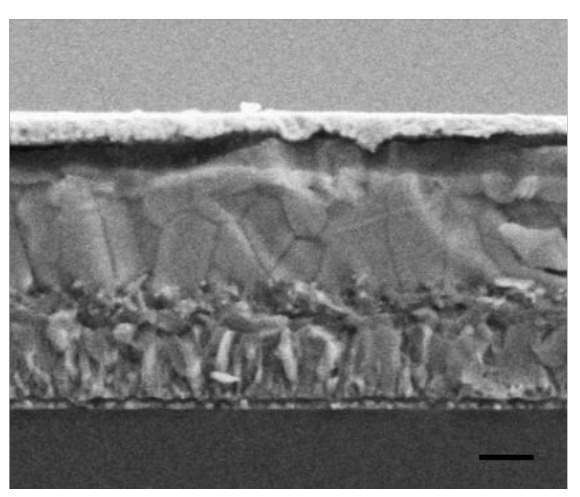

(b)

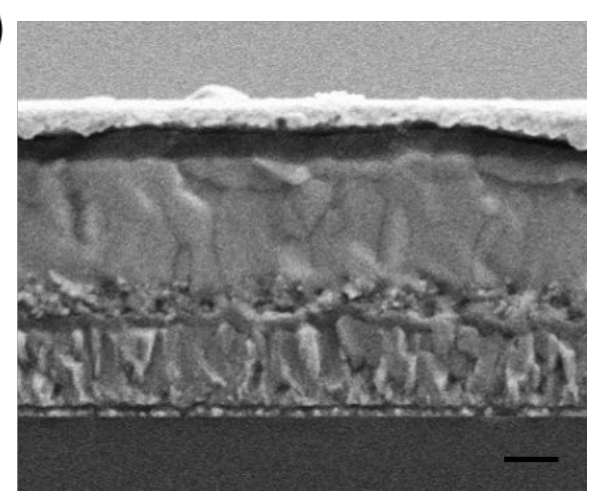

Figure S2. Cross-view SEM image of a) $\mathrm{MAPbI}_{3}$ and $\left.b\right)(\mathrm{TMH})_{\mathrm{x}} \mathrm{MA}_{1-\mathrm{x}} \mathrm{PbI}_{3}(\mathrm{x}=7.5 \%)$ films. The scale bar is $200 \mathrm{~nm}$.

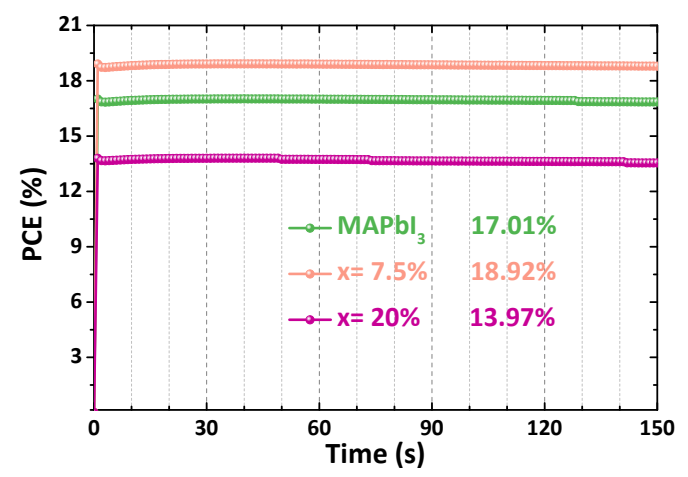

Figure S3. Stabilized power output at maximum power point as a function of time for the best performing $\mathrm{MAPbI}_{3}$ and $(\mathrm{TMH})_{\mathrm{x}} \mathrm{MA}_{1-\mathrm{x}} \mathrm{PbI}_{3}(\mathrm{x}=7.5 \%$ and $20 \%)$ devices.
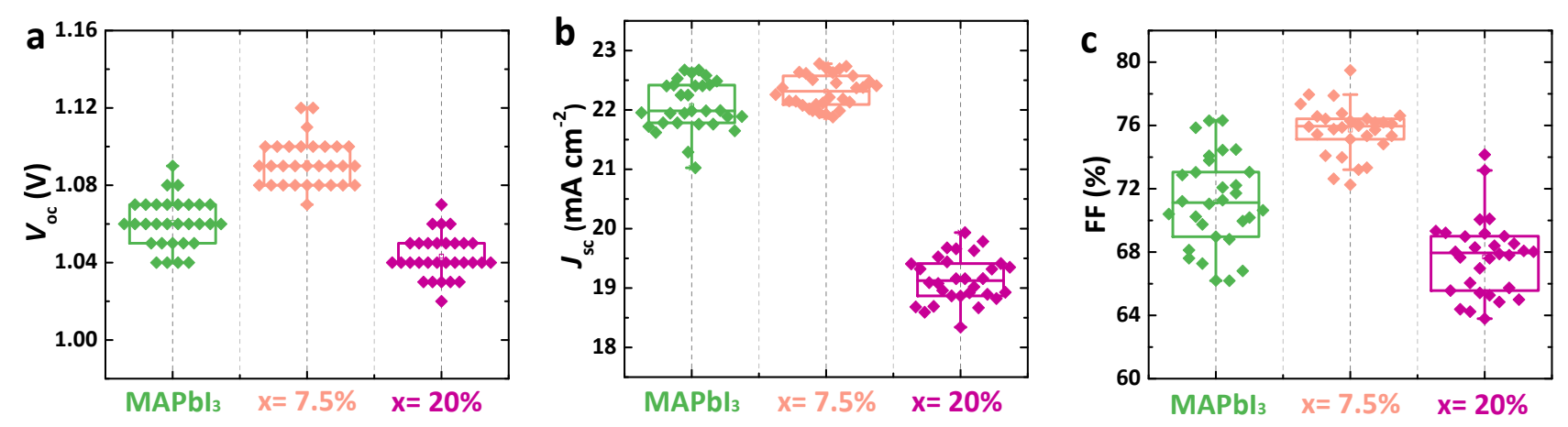

Figure S4. The statistical parameters of a) $V_{\mathrm{oc}}$, b) $J_{\mathrm{sc}}$ and c) $\mathrm{FF}$ of $\mathrm{MAPbI}_{3}$ and $(\mathrm{TMH})_{\mathrm{x}} \mathrm{MA}_{1-\mathrm{x}} \mathrm{PbI}_{3}(\mathrm{x}=7.5 \%$ and 20\%) PSCs among 30 as-prepared devices. 


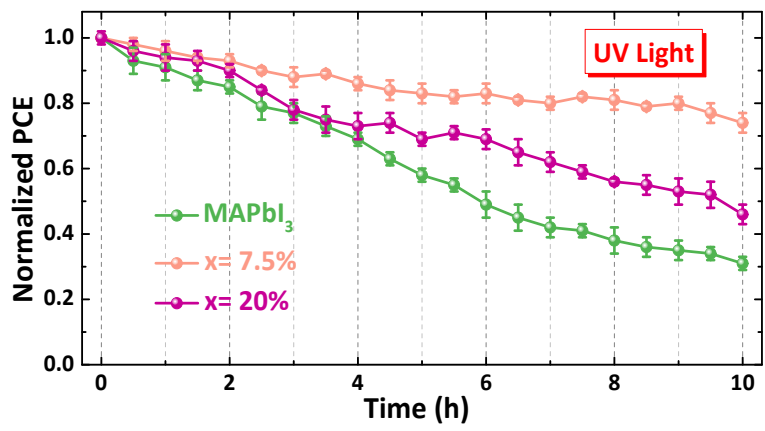

Figure S5. Normalized $\mathrm{PCE}$ variation curves of $\mathrm{MAPbI}_{3}$ and $(\mathrm{TMH})_{\mathrm{x}} \mathrm{MA}_{1-\mathrm{x}} \mathrm{PbI}_{3}(\mathrm{x}=7.5 \%$ and $20 \%) \mathrm{PSCs}$ when exposed to continuous UV irradiation.

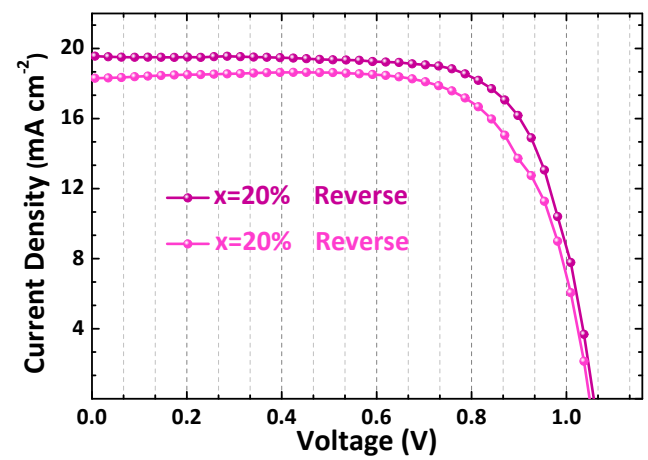

Figure S6. $J-V$ curves of $(\mathrm{TMH})_{\mathrm{x}} \mathrm{MA}_{1-\mathrm{x}} \mathrm{PbI}_{3}(\mathrm{x}=20 \%)$ perovskite devices under reverse and forward scan directions.

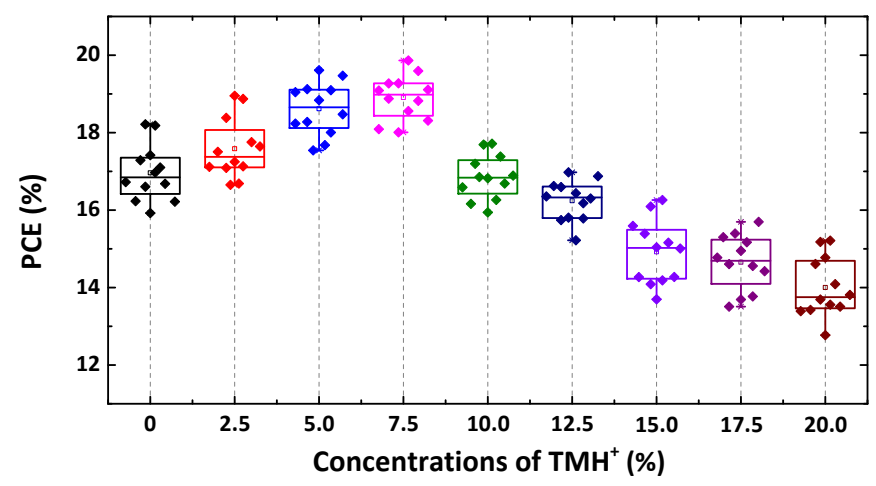

Figure S6. PCE statistics of the devices based on controlled $\mathrm{MAPbI}_{3}$ films $(\mathrm{x}=0)$ and $(\mathrm{TMH})_{\mathrm{x}} \mathrm{MA}_{1-\mathrm{x}} \mathrm{PbI}_{3}$ films with different TMH-incorporation concentrations $(x=2.5 \%, 5 \%, 7.5 \%, 10 \%, 12.5 \%, 15 \%, 17.5 \%$ and $20 \%)$ 

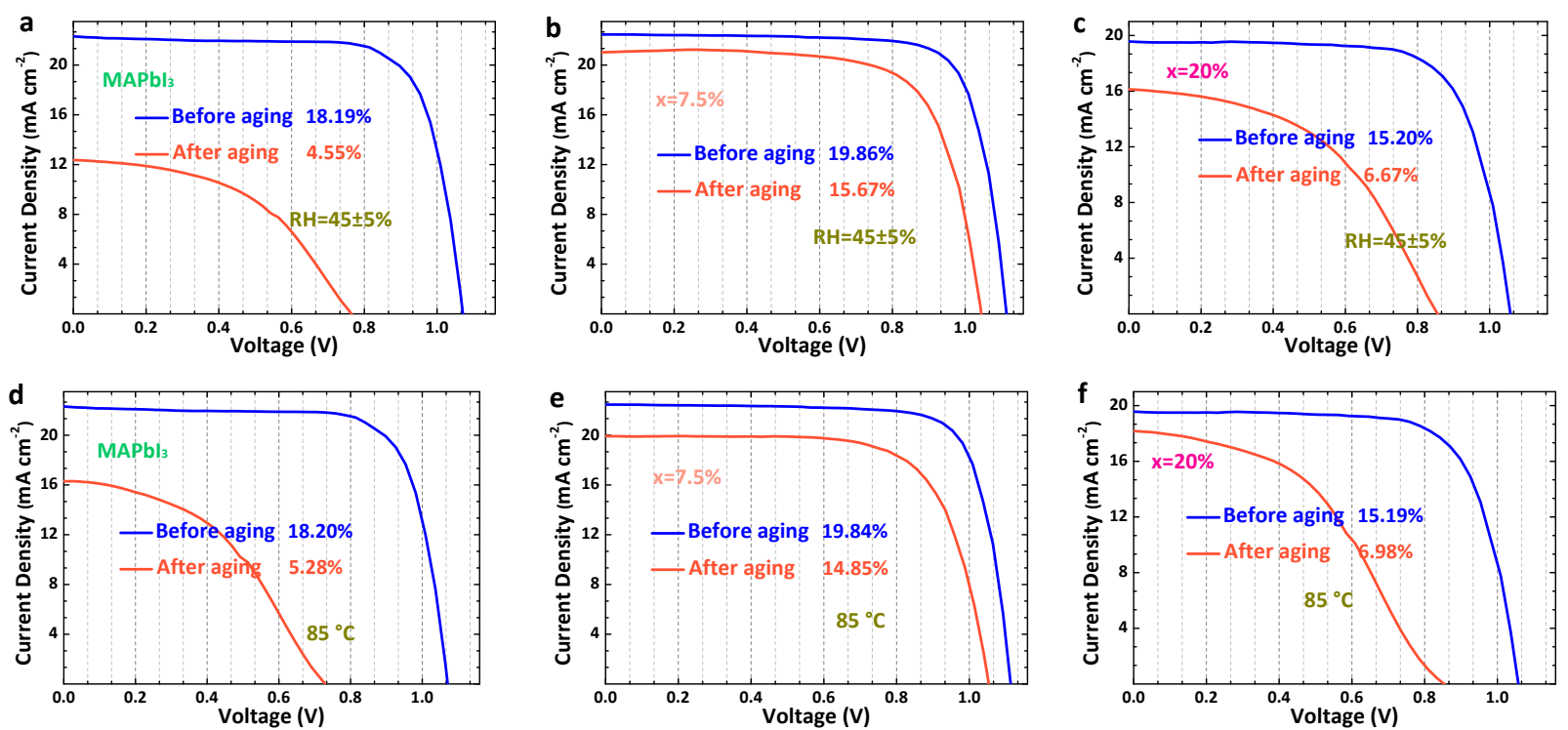

Figure S8. $J-V$ curves of non-encapsulated $\mathrm{MAPbI}_{3}$ and $(\mathrm{TMH})_{\mathrm{x}} \mathrm{MA}_{1-\mathrm{x}} \mathrm{PbI}_{3}(\mathrm{x}=7.5 \%$ and $20 \%) \mathrm{PSCs}$ before and after aging.

Table S1. Atomic contents of C 1s and N 1s in different films from XPS spectra.

\begin{tabular}{ccc}
\hline Sample & Element & Atomic \% \\
\hline $\mathrm{MAPbI}_{3}$ & $\mathrm{C} 1 \mathrm{~s}$ & 76.73 \\
& $\mathrm{~N} 1 \mathrm{~s}$ & 5.37 \\
$\mathrm{x}=7.5 \%$ & $\mathrm{C} 1 \mathrm{~s}$ & 74.85 \\
& $\mathrm{~N} 1 \mathrm{~s}$ & 6.52 \\
\hline
\end{tabular}


Table S2. Photovoltaic parameters of $\mathrm{MAPbI}_{3}$ and $(\mathrm{TMH})_{\mathrm{x}} \mathrm{MA}_{1-\mathrm{x}} \mathrm{PbI}_{3}(\mathrm{x}=2.5 \%, 5 \%, 7.5 \%, 10 \%$ and $20 \%)$ PSCs.

$\begin{array}{lcccc}\text { Device } & J_{\mathrm{sc}}\left(\mathrm{mA} \mathrm{cm}^{-2}\right) & V_{\text {oc }}(\mathrm{V}) & \mathrm{FF}(\%) & \text { PCE (\%) } \\ \mathrm{MAPbI}_{3} & 22.77 & 1.07 & 74.73 & 18.22 \\ \mathrm{x}=2.5 \% & 22.87 & 1.08 & 76.78 & 18.95 \\ \mathrm{x}=5 \% & 22.93 & 1.11 & 77.15 & 19.60 \\ \mathrm{x}=7.5 \% & 22.90 & 1.11 & 77.84 & 19.86 \\ \mathrm{x}=10 \% & 21.57 & 1.10 & 74.92 & 17.71 \\ \mathrm{x}=20 \% & 19.89 & 1.06 & 72.20 & 15.21\end{array}$

Table S3. Photovoltaic parameters of the $\mathrm{MAPbI}_{3}$ and $(\mathrm{TMH})_{\mathrm{x}} \mathrm{MA}_{1-\mathrm{x}} \mathrm{PbI}_{3}(\mathrm{x}=7.5 \%$ and $20 \%)$ devices under reverse and forward scan directions.

\begin{tabular}{|ccccc}
\hline Device & $J_{\mathrm{sc}}\left(\mathrm{mA} \mathrm{cm}^{-2}\right)$ & $V_{\mathrm{oc}}(\mathrm{V})$ & FF $(\%)$ & PCE (\%) \\
\hline $\mathrm{MAPbI}_{3}$ Reverse & 22.77 & 1.07 & 74.73 & 18.22 \\
\hline $\mathrm{MAPbI}_{3}$ Forward & 21.57 & 1.07 & 73.25 & 16.85 \\
\hline $\mathrm{X}=7.5 \%$ Reverse & 22.90 & 1.11 & 77.84 & 19.86 \\
\hline $\mathrm{x}=7.5 \%$ Forward & 22.64 & 1.11 & 77.14 & 19.34 \\
\hline $\mathrm{x}=20 \%$ Reverse & 19.89 & 1.06 & 72.20 & 15.21 \\
\hline $\mathrm{x}=20 \%$ Forward & 18.35 & 1.05 & 70.72 & 13.62 \\
\hline
\end{tabular}


Table S4. Atomic contents of C 1s and N 1s in different films from XPS spectra.

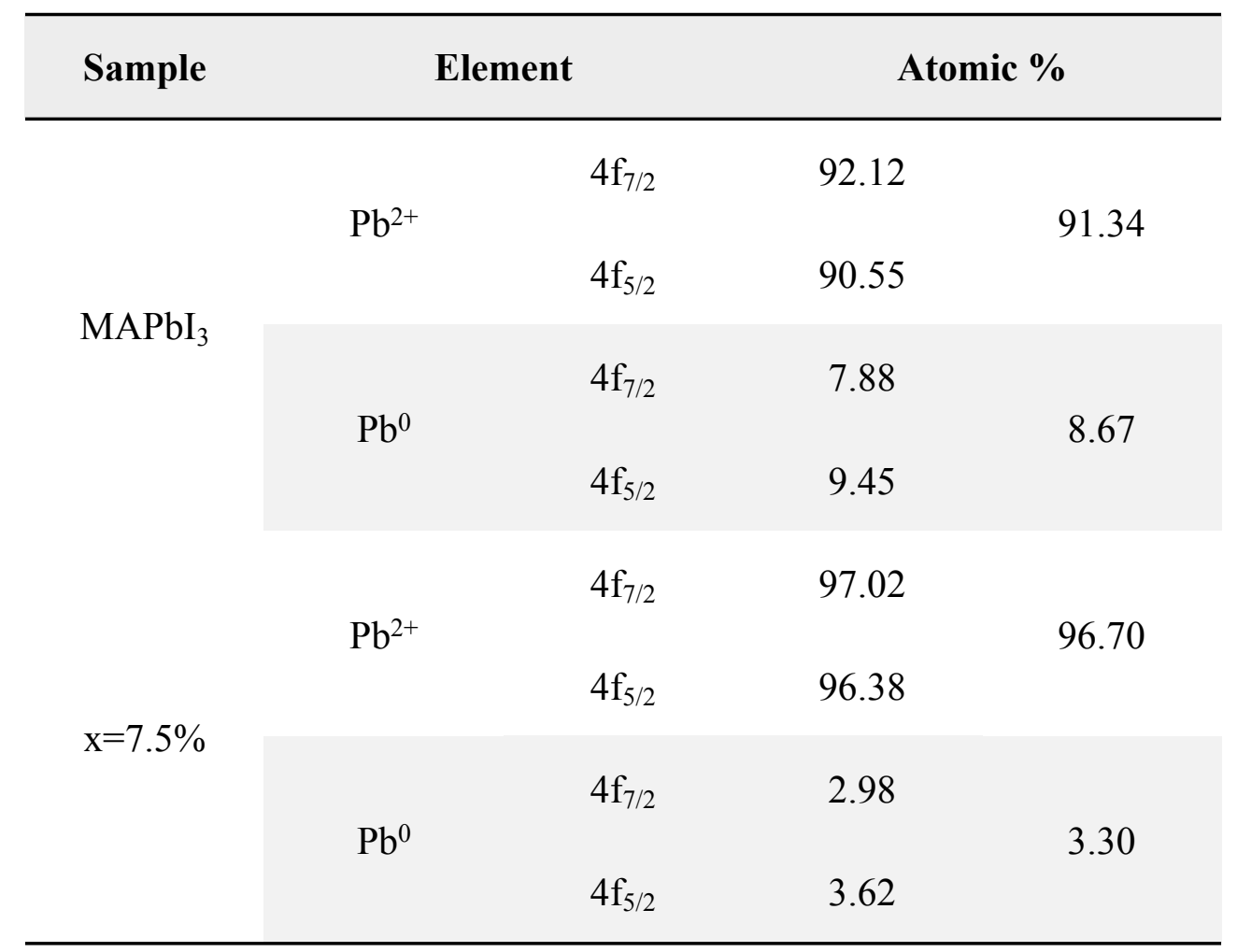

\section{References}

(1) Giordano, T. J.; Palenik, G. J.; Sisler, H. H. Crystal Structures of 2,2-Dimethyltriazanium Chloride and 1,1,1-Trimethylhydrazinium Chloride. Inorg. Chem. 1991, 15, 751-754.

(2) Saparov, B.; Mitzi, D. B. Organic-Inorganic Perovskites: Structural Versatility for Functional Materials Design. Chem. Rev. 2016, 116, 4558-4596. 